\title{
UMA REFLEXÃO DIDÁTICA ACERCA DA DISTRIBUIÇÃO DE GÊNEROS TEXTUAIS PARA O ENSINO FUNDAMENTAL
}

\section{A DIDACTIC REFLECTION ON DISTRIBUTION OF TEXTUAL GENRES TO THE PRIMARY SCHOOL}

\section{João Bosco Figueiredo-Gomes*}

Universidade do Estado do Rio Grande do Norte, Mossoró, RN, Brasil

Arisberto Gomes de Souza**

Universidade Federal do Rio Grande do Norte, Natal, Rio Grande do Norte, Brasil

Resumo: Considerando o interesse pelo estudo e pelo ensino de gêneros textuais nas últimas três décadas, o presente artigo apresenta a análise de uma colecção de livros didáticos de língua portuguesa do Ensino Fundamental II, que objetivou verificar se o livro didático oportuniza uma compreensão acerca dos diferentes gêneros textuais tanto pelo aluno, em relação ao contexto de uso social, quanto pelo professor, em relação a parâmetros para a análise e escolha de coleções didáticas. 0 arcabouço teórico-metodológico baseou-se principalmente nas contribuiç̃oes do Interacionismo Sociodiscursivo: Bronckart $(1999,2003)$ e Schneuwly e Dolz $(2004)$; nos estudos de Marcuschi $(2002,2008)$ e nas orientações sobre 0 ensino de língua materna contidas nos Parâmetros Curriculares Nacionais (BRASIL, 1998). Os resultados fornecem parâmetros para a análise, escolha e organização de coleç̃ões didáticas, bem como sugestões de implementações pedagógicas com vistas ao ensino de língua portuguesa.

Palavras-chave: interacionismo sociodiscursivo; ensino; gêneros textuais; livro didático; língua portuguesa.

Abstract: Considering the interest on the studies about textual genre and its teaching in the three last decades, the present article presents a report of an analysis of collection of didactic books of Portuguese language of the Primary School II, which aimed at verifying if the didactic book enables a comprehension about different textual genres as for the student, in relation to the context and social use, as well as for the teacher, in relation to parameters in order to do an analysis and choice of didactic collection books. The theoretical methodological framework based mainly in the contributions of Interactionism Socio-discursive: Bronckart $(1999,2003)$ and Schneuwly and Dolz (2004); in the studies by Marcuschi $(2002,2008)$ and in the orientations about the teaching of mother language contained in the National Curriculum Guidelines - PCN (BRASIL, 1998). The results provided a reflection that offers parameters to the analysis, choice and organization of didactic collections, as well as suggestions of pedagogic implementation towards the teaching of Portuguese language.

Keywords: Interactionism Socio-discursive; Teaching; Textual Genre; Didactic Book; Portuguese language.

* Professor Doutor da Universidade do Estado do Rio Grande do Norte - UERN, Brasil; boscofigueiredo@yahoo.com.br

** Doutorando em Estudos da Linguagem pela Universidade Federal do Rio Grande do Norte UFRN, Brasil; aarisba@hotmail.com 
Linha D’Água (Online), São Paulo, v. 28, n. 2, p. 44-66, dez 2015

\section{Introdução}

Um ensino de língua baseado na concepção de língua enquanto interação pressupõe considerá-la como prática social. Nessa perspectiva, as atividades desenvolvidas no espaço escolar devem se aproximar ao máximo daquelas realizadas fora desse espaço. Souza, Leite e Albuquerque (2006) afirmam que é importante trazer, para o convívio efetivo dos alunos, a diversidade de gêneros textuais presentes nos espaços extraescolares. Por meio dos trabalhos com os gêneros textuais, o aluno irá perceber as características que são inerentes a cada texto, ampliando, então, seu potencial comunicativo nos âmbitos da escrita, leitura e oralidade.

Com vistas a uma maior compreensão de um trabalho dessa natureza, o presente artigo objetiva averiguar se o livro didático de língua portuguesa (LDLP) dos ciclos finais ( $6^{\circ}$ ao $9^{\circ}$ ano) do Ensino Fundamental instrumentaliza o aluno para a compreensão e a produção dos diferentes gêneros textuais, observando o contexto de uso social, e se oferece ao professor parâmetros para a análise e escolha de coleções didáticas.

O presente artigo apresenta a seguinte organização: primeiramente, apresentamos o que preconizam os PCN acerca dos gêneros textuais e o respaldo teórico do interacionismo sociodiscursivo (ISD); depois, vêm os procedimentos metodológicos que desenham os passos da investigação; em seguida, está a análise dos gêneros textuais na coleção didática; e, por fim, com base nos resultados, apresentamos algumas sugestões de implementações pedagógicas para o ensino de língua portuguesa.

\section{Gêneros textuais segundo os PCN e os pressupostos do interacionis- mo sociodiscursivo}

O advento dos PCN (BRASIL, 1998) levou o estudo dos gêneros textuais a ser nacionalmente concebido enquanto objeto de ensino de língua materna. $\mathrm{O}$ documento salienta que "a noção de gênero, constitutiva do texto, precisa ser tomada como objeto de ensino" (BRASIL, 1998, p. 23). O documento sugere, entre outras coisas, que, em língua materna, o ensino deve priorizar atividades que desenvolvam nos alunos a competência comunicativa, expandindo as várias possibilidades do uso da linguagem, em qualquer forma e contexto de realização, conforme podemos verificar na seguinte citação: "no processo de ensino e aprendizagem dos diferentes ciclos do ensino fundamental espera-se que o aluno amplie o domínio ativo do discurso nas diversas situações comunicativas" (BRASIL, 1998, p.32).

Entendemos a noção de gênero textual, conforme a definição de Bakhtin (2000, p. 279) para "gênero do discurso", como um enunciado relativamente 
estável, historicamente determinado e disponível na cultura, fixando-se basicamente na conceituação de enunciado como forma, oral ou escrita, de utilização concreta e individual da língua por integrantes de uma ou outra esfera da atividade humana e caracterizado pela fusão de três elementos que estão presentes nos PCN (BRASIL, 1998), no conteúdo referente à análise linguística: a) o conteúdo temático - aquilo que pode ser dito em um dado gênero; b) a construção composicional - qual é a estrutura particular dos textos pertencentes ao gênero; e c) o estilo - que se refere à seleção de recursos disponibilizados pela língua, orientada pela posição enunciativa do produtor do texto. Acrescentamos ainda a esses elementos, para dar conta do ensino de línguas, o objetivo, o qual se refere à finalidade do texto - o "para quê"-, e o destinatário - "para quem" se produz.

Acerca da didatização dos gêneros, os PCN ressaltam a ideia de que, pelo trabalho com os gêneros textuais, as capacidades dos alunos são desenvolvidas tanto para fins de produção e compreensão de textos, quanto para a reflexão sobre a língua, em textos orais ou escritos. Dentre as sugestões contidas nos PCN, algumas apontam para um estudo em forma espiral, ou seja, os conteúdos devem ser constantemente retomados. Há também uma intenção de sugerir um trabalho didático que contemple a diversidade de gêneros textuais e as propriedades tipológicas que envolvem os textos.

É possível observar que muitas das orientações teórico-pedagógicas trazidas pelos PCN (BRASIL, 1998) traduzem os pressupostos do ISD, talvez porque, nessa vertente, constem vastas referências ao modo de pensar e fazer o ensino com base nos gêneros. Muitas dessas reflexões podem ser encontradas em Schneuwly e Dolz (2004), em cuja obra são exploradas algumas noções como, por exemplo, as de sequência didática, progressão curricular e agrupamento de gêneros, especificamente voltadas às questões do ensino dos gêneros textuais.

Schneuwly e Dolz (2004) enfatizam que o ensino de uma determinada língua deve se dar numa perspectiva interacional. Dessa forma, toda e qualquer ação deve considerar o contexto histórico e social em que as atividades linguísticas ocorrem. Para os autores, as ações linguísticas que ocorrem por meio de construções sociais conduzem à conscientização, e, por conseguinte, à aprendizagem e ao desenvolvimento comunicativo. Eles acreditam que o ensino de língua materna deve ser pautado por textos e por isso sugerem o trabalho por meio da experimentação dos diferentes gêneros textuais orais e escritos pelos alunos.

A própria noção de gênero textual como ferramenta, defendida pela escola de Genebra, aponta para uma questão didática. Para Bronckart (1999), o gênero como ferramenta atua no processo de aprendizagem e é encarado como um verdadeiro instrumento para o desenvolvimento das habilidades linguísticas. Segundo 
Schneuwly e Dolz (2004), o gênero pode ser considerado um instrumento que fornece suporte para atividades nas situações de comunicação, tornando-se uma referência para os aprendizes.

A consolidação da didatização dos gêneros textuais pode se dar por meio de sequências didáticas que são "um conjunto de atividades escolares organizadas, de maneira sistemática, em torno de um gênero textual" (DOLZ; NOVERRAZ; SCHNEUWLY, 2004, p. 97). São as sequências didáticas as responsáveis pelo desenvolvimento de três grandes fatores: as práticas de linguagem (materializadas em gêneros textuais) que são objeto de ensino-aprendizagem; as capacidades de linguagem dos alunos; e as estratégias de ensino desenvolvidas pela sequência didática (SCHNEUWLY; DOLZ, 2004).

A construção de uma sequência didática requer a escolha do(s) gênero(s) objeto(s) de ensino, pautada em objetivos claros. Depois disso, é necessária ainda a pesquisa do gênero em diferentes fontes, para, a partir daí, fazer a análise do seu contexto de produção, organização textual e aspectos linguístico-discursivos.

Assim é que a produção e a leitura dos variados gêneros na escola contribuem para o efetivo pensar e repensar das atividades desenvolvidas no meio social em que estamos inseridos, proporcionando aos alunos a ampliação da sua competência comunicativa. $\mathrm{O}$ ensino de língua voltado ao trabalho com gêneros textuais possibilita aos alunos novos conhecimentos linguísticos, uma vez que eles estariam experimentando e refletindo acerca de gêneros que circulam no meio social.

A partir de objetivos pedagógicos, Schneuwly e Dolz (2004) agrupam os gêneros com o propósito de viabilizar o trabalho na escola. $\mathrm{O}$ agrupamento acontece a partir dos seguintes fatores: a organização dos gêneros textuais pelas semelhanças apresentadas nas situações de produção, caracterizadas em função das capacidades de linguagem envolvidas na produção e compreensão desses gêneros; a tipologia geral; e o domínio social da comunicação a que pertencem os textos. A divisão consiste em organizar os gêneros pelas semelhanças entre suas situações de produção, a saber:

a) gêneros da ordem do narrar - cujo domínio social é o da cultura literária ficcional, e a capacidade de linguagem dominante é voltada à recriação da realidade, por meio da montagem de uma intriga no domínio do verossímil. Exemplos do gênero: conto maravilhoso, conto de fadas, fábula, lenda, narrativa de aventura, narrativa de ficção cientifica, narrativa de enigma, narrativa mítica, sketch ou história engraçada, biografia romanceada, 
romance, romance histórico, novela fantástica, conto, crônica literária, adivinha, piada e afins.

b) gêneros da ordem do relatar - cujo domínio social é o da memória e o da documentação das experiências humanas vivenciadas. A capacidade de linguagem dominante é a de representação pelo discurso de experiências vividas e situadas no tempo. Exemplos do gênero: relato de experiência vivida, relato de viagem, diário íntimo, testemunho, anedota ou caso, autobiografia, curriculum vitae, notícia, reportagem, crônica social, crônica esportiva, histórico, relato histórico, ensaio ou perfil biográfico, biografia e afins.

c) gêneros da ordem do argumentar - cujo domínio social é o da discussão de assuntos sociais controversos, visando a um entendimento e posicionamento perante eles; e as capacidades de linguagem dominantes são as que envolvem a habilidade de sustentar, refutar e negociar posições. Exemplos do gênero: textos de opinião, diálogo argumentativo, carta de leitor, carta de solicitação, deliberação informal, debate regrado, assembleia, discurso de defesa (advocacia), discurso de acusação (advocacia), resenha crítica, artigos de opinião ou assinados, editorial, ensaio e afins.

d) gêneros da ordem do expor - veiculam o conhecimento mais sistematizado transmitido culturalmente - conhecimento científico e afins. A capacidade de linguagem dominante é a apresentação textual de diferentes formas de saberes. Exemplos do gênero: texto expositivo, exposição oral, seminário, conferência, comunicação oral, palestra, entrevista de especialista, verbete, artigo enciclopédico, texto explicativo, tomada de notas, resumo de textos expositivos e explicativos, resenha, relatório científico, relatório oral de experiência e afins;

e) gêneros da ordem do instruir ou do prescrever - englobam textos variados de instrução, regras e normas, e pretendem, em diferentes domínios, a prescrição ou regulamentação de ações. A capacidade de linguagem dominante é a regulação mútua de comportamentos. Exemplos do gênero: instruções de montagem, receita, bula, regulamento, regras de jogo, instruções de uso, comandos diversos, textos prescritivos, entre outros.

Dolz e Schneuwly (2004) argumentam que cada um dos cinco agrupamentos favorece o desenvolvimento de capacidades necessárias para o domínio dos gêneros, construídas ao longo da escolaridade, uma vez que apresentam 
ampla diversidade de gêneros. Os agrupamentos são necessários, ainda, porque atendem a diferentes fatores: o pedagógico, por oferecer aos alunos diferentes vias de acesso à escrita; o didático, ao explicar as especificidades de funcionamento dos gêneros e tipos textuais; o psicológico, ao exigir numerosas operações de linguagem; e, por último, as finalidades sociais, ao desenvolverem a capacidade de os alunos refletirem sobre suas relações com o mundo e consigo mesmo.

Outro conceito que deve estar presente na agenda escolar de discussões sobre os gêneros textuais é o de esferas da atividade humana (BAKHTIN, 1997. Todas as esferas da atividade humana fazem uso da língua para elaborar seus enunciados de acordo com as suas necessidades. Essas esferas de utilização da língua são múltiplas e cada uma delas engloba uma determinada singularidade de gêneros textuais. Bakhtin (1997) defende a ideia de que, nas diferentes esferas de comunicação humana, as formas de interação diferem, acarretando assim uma vasta variedade de gêneros, pois elas "estão sempre relacionadas com a utilização da língua, a riqueza e a variedade dos gêneros” (p. 279).

Trabalhar a diversidade de gêneros existentes nas diferentes esferas de comunicação aproxima o aluno dos discursos que ocorrem no meio social, dando condições para que ele entre em contato com gêneros textuais que são produzidos fora da escola, em diferentes áreas de conhecimento, e reconheça as particularidades do maior número de possibilidades comunicativas, estando apto a utilizá-las de modo competente quando as necessidades de interação social forem requeridas.

O conceito de esferas de comunicação de Bakhtin (1997) foi amplamente debatido, chegando a ser modificado e ampliado por alguns estudiosos, recebendo, inclusive, outras denominações, como por exemplo, "domínio social de comunicação", para a escola de Genebra (SCHNEUWLY; DOLZ, 2004), e "domínio discursivo" para Marcuschi (2002).

Para Marcuschi (2002), os domínios discursivos são, na verdade, "as grandes esferas da atividade humana em que os textos circulam” (p. 24). Diferentemente da teoria da escola de Genebra, para o estudioso, o domínio discursivo não constitui um princípio de classificação de textos, mas indica instâncias discursivas. Marcuschi (2008) argumenta que os domínios discursivos podem se fazer presentes tanto numa esfera da vida social quanto institucional. Ele propõe uma classificação dos gêneros textuais orais e escritos e os distribui em 12 domínios discursivos, conforme Quadro 1: 


\section{Linha D'Água (Online), São Paulo, v. 28, n. 2, p. 44-66, dez 2015}

\begin{tabular}{|c|c|c|}
\hline $\begin{array}{l}\text { DOMÍNIOS } \\
\text { DISCURSIVOS }\end{array}$ & $M^{1}$ & GÊNEROS TEXTUAIS \\
\hline \multirow[t]{2}{*}{ 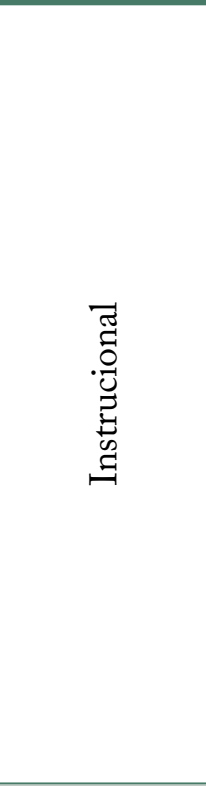 } & $\mathrm{E}$ & $\begin{array}{l}\text { artigo científico; verbete de enciclopédia; relatório científico; notas de aula; nota } \\
\text { de rodapé; diário de campo; tese; dissertação; monografia; glossário; artigo de } \\
\text { divulgação científica; tabela; mapa; gráfico; resumo de artigos de livros; resumo de } \\
\text { livro; resumo de conferência; resenha; comentários; biografia; projetos; solicitação } \\
\text { de bolsa; cronograma de trabalho; organograma de atividade; monografia de } \\
\text { curso; monografia de disciplina; definição; autobiografia; manual de ensino; } \\
\text { bibliografia; ficha catalográfica; memorial; curriculum vitae; parecer técnico; } \\
\text { verbete; parecer sobre tese; parecer sobre artigo; parecer sobre projeto; carta de } \\
\text { apresentação; carta de recomendação; ata de reunião; sumário; índice remissivo; } \\
\text { diploma; índice onomástico; dicionário; prova de língua; prova de vestibular; } \\
\text { prova de múltipla escolha; diploma; certificado de especialização; certificado de } \\
\text { proficiência; atestado de participação; epígrafe }\end{array}$ \\
\hline & $\mathrm{O}$ & $\begin{array}{l}\text { conferência; debate; discussão; exposição; comunicação; aula participativa; aula } \\
\text { expositiva; entrevista de campo; exame oral; exame final; seminário de iniciantes; } \\
\text { seminário avançado; seminário temático; colóquio; prova oral; arguição de tese; } \\
\text { arguição de dissertação; entrevista de seleção de concurso; aula de concurso; aula } \\
\text { em vídeo; aula pelo rádio; aconselhamento }\end{array}$ \\
\hline \multirow[t]{2}{*}{ 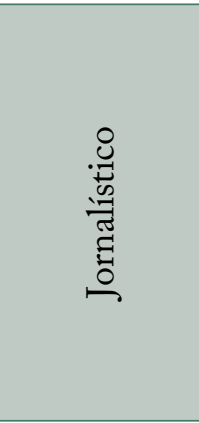 } & $\mathrm{E}$ & $\begin{array}{l}\text { editorial; notícia; reportagem; nota social; artigo de opinião; comentário; jogos; } \\
\text { história em quadrinhos; palavra cruzada; crônica policial; crônica esportiva; } \\
\text { entrevista jornalística; anúncios classificados; anúncios fúnebres; carta do leitor; } \\
\text { carta ao leitor; resumo de novela; reclamações; capa de revista; expediente; } \\
\text { boletim do tempo; sinopse de novela; resumo de filme; cartum; caricatura; } \\
\text { enquete; roteiros; errata; charge; programação semanal; agenda de viagem }\end{array}$ \\
\hline & $\mathrm{O}$ & $\begin{array}{l}\text { entrevista jornalística; entrevista televisiva; entrevista radiofônica; entrevista } \\
\text { coletiva; notícia de rádio; notícia de TV; reportagem ao vivo; comentários; } \\
\text { discussões; debate; apresentações; programa radiofônico; boletim do tempo }\end{array}$ \\
\hline \multirow[t]{2}{*}{ 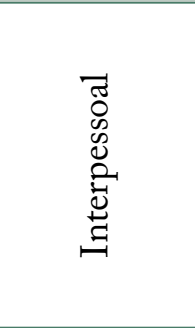 } & $\mathrm{E}$ & $\begin{array}{l}\text { carta pessoal; carta comercial; carta aberta; carta do leitor; carta oficial; carta- } \\
\text { convite; cartão de visita; e-mail; bilhete; ata; telegrama; memorando; boletim; } \\
\text { relato; agradecimento; convite; advertência; informe; diário pessoal; aviso fúnebre; } \\
\text { volante; lista de compras; endereço postal; endereço eletrônico; autobiografia; } \\
\text { formulário; placa; mapa; catálogo; papel timbrado }\end{array}$ \\
\hline & $\mathrm{O}$ & $\begin{array}{l}\text { recado; conversação espontânea; telefonema; bate-papo virtual; convite; } \\
\text { agradecimento; advertência; aviso; ameaça; provérbio }\end{array}$ \\
\hline \multirow[t]{2}{*}{ 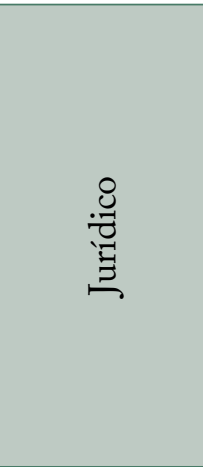 } & $\mathrm{E}$ & $\begin{array}{l}\text { contrato; lei; regimento; estatuto; certidão de batismo; certidão de casamento; } \\
\text { certidão de óbito; certidão de bons antecedentes; certidão negativa; atestado; } \\
\text { certificado; diploma; normas; regras; parecer; boletim de ocorrência; edital de } \\
\text { convocação; edital de concurso; aviso de licitação; auto de penhora; auto de } \\
\text { avaliação; documentos pessoais; requerimento; autorização de funcionamento; } \\
\text { alvará de licença; alvará de soltura; alvará de prisão; sentença de condenação; } \\
\text { citação criminal; mandado de busca; decreto-lei; medida provisória; desmentido; } \\
\text { edital; regulamento; advertência }\end{array}$ \\
\hline & U & $\begin{array}{l}\text { tomada de depoimento, arguição; declaração; exortação; depoimento; inquérito } \\
\text { judicial; inquérito policial; ordem de prisão }\end{array}$ \\
\hline
\end{tabular}

Quadro 1: Gêneros textuais segundo a modalidade de usos da língua por domínios discursivos [Continua]

\section{${ }^{1}(M)$ para modalidade de uso da língua; $(E)$ para escrita; $(O)$ para oralidade.}




\section{Linha D'Água (Online), São Paulo, v. 28, n. 2, p. 44-66, dez 2015}

\begin{tabular}{|c|c|c|}
\hline \multirow[t]{2}{*}{ 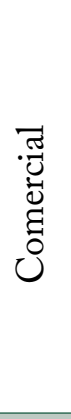 } & $\mathrm{E}$ & $\begin{array}{l}\text { rótulo; nota de venda; fatura; nota de compra; classificados; publicidade; } \\
\text { comprovante de pagamento; nota promissória; nota fiscal; boleto; boletim de } \\
\text { preços; logomarca; comprovante de renda; carta comercial; parecer de consultoria; } \\
\text { formulário de compra; carta-resposta; comercial; memorando; nota de serviço; } \\
\text { controle de estoque; controle de venda; copyright; bilhete de avião; bilhete de } \\
\text { ônibus; carta de representação; certificado de garantia; atestado de qualidade; lista } \\
\text { de espera; balança comercial }\end{array}$ \\
\hline & $\mathrm{O}$ & $\begin{array}{l}\text { publicidade de feira; publicidade de TV; publicidade de rádio; refrão de feira; } \\
\text { refrão de carro de venda de rua }\end{array}$ \\
\hline \multirow{2}{*}{ 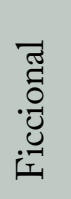 } & $\mathrm{E}$ & $\begin{array}{l}\text { épica-lírica-dramática; poema; conto, mito; peça de teatro; lenda; parlenda; fábula; } \\
\text { história em quadrinhos; romance; drama; crônica; roteiro de filme }\end{array}$ \\
\hline & $\mathrm{O}$ & fábula; conto; lenda; poema; declamação; encenação \\
\hline \multirow{2}{*}{ 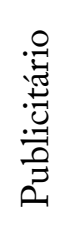 } & $\mathrm{E}$ & $\begin{array}{l}\text { propaganda; publicidade; anúncio; cartaz; folheto; logomarca; aviso; necrológio; } \\
\text { outdoors; inscrições em muros; inscrições em banheiros; placa; endereço postal; } \\
\text { endereço eletrônico; endereço de internet }\end{array}$ \\
\hline & $\mathrm{O}$ & publicidade na TV; publicidade no rádio \\
\hline \multirow{2}{*}{ 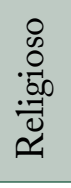 } & $\mathrm{E}$ & $\begin{array}{l}\text { oração; reza; catecismo; homilia; hagiografia; cântico religioso; missal; bula papal; } \\
\text { jaculatória; penitência; encíclica papal }\end{array}$ \\
\hline & $\mathrm{O}$ & $\begin{array}{l}\text { sermão; confissão; reza; cantorias; oração; lamentações; benzeção; cantos } \\
\text { medicinais }\end{array}$ \\
\hline \multirow{2}{*}{ 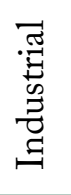 } & $\mathrm{E}$ & $\begin{array}{l}\text { instruções de montagem; descrição de obras; código de obras; aviso; controle de } \\
\text { estoque; atestado de validade; manual de instrução }\end{array}$ \\
\hline & $\mathrm{O}$ & ordens \\
\hline \multirow{2}{*}{ 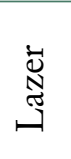 } & $\mathrm{E}$ & piada; jogos; adivinha; história em quadrinhos; palavra cruzada; horóscopo \\
\hline & $\mathrm{O}$ & fofoca; piada; adivinha; jogos teatrais \\
\hline \multirow{2}{*}{ 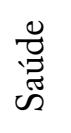 } & $\mathrm{E}$ & receita médica; bula de remédio; parecer médico; receita caseira; receita culinária \\
\hline & $\mathrm{O}$ & consulta; entrevista médica; conselho médico \\
\hline \multirow{2}{*}{ 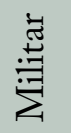 } & $\mathrm{E}$ & ordem do dia; roteiro de cerimônia oficial; roteiro de formatura; lista de tarefas \\
\hline & $\mathrm{O}$ & ordem do dia \\
\hline
\end{tabular}

Quadro 1: Gêneros textuais segundo a modalidade de usos da língua por domínios discursivos [Continuação]

Fonte: Adaptação de Marcuschi (2008, p. 194-6)

A distribuição proposta apresenta gêneros textuais das modalidades oral e escrita de cada domínio discursivo, das mais diferentes ordens.

Objetivando refletir sobre uma proposta de distribuição adequada à realidade do aluno, contabilizamos a distribuição de gêneros por domínio discursivo (cf. Quadro 1), proposta por Marcuschi (2008), e a dividimos pelo total do quadro 
Linha D'Água (Online), São Paulo, v. 28, n. 2, p. 44-66, dez 2015

geral. Obtivemos, então, o percentual da distribuição de gênero/domínio, que pode sugerir uma proporção para a prática educacional, como podemos verificar no Gráfico 1:

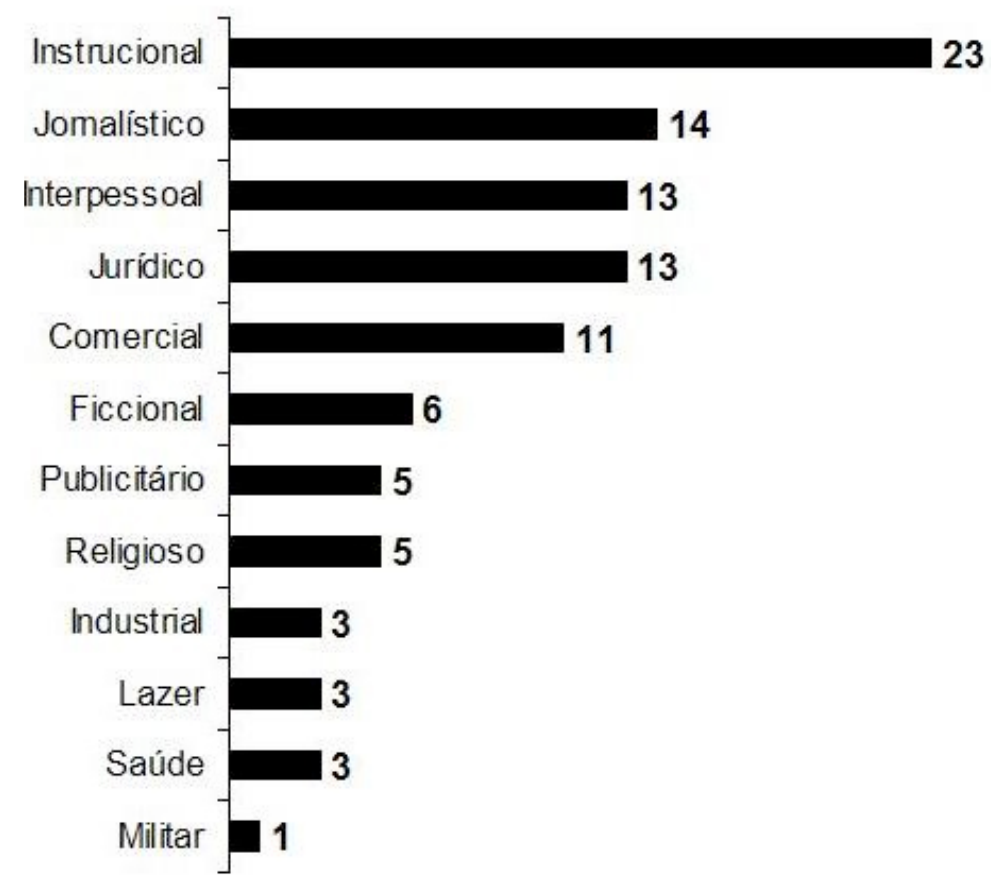

Gráfico 1: Percentuais da proposta de organização dos gêneros textuais segundo os domínios discursivos a partir de Marcuschi (2008)

Fonte: Figueiredo-Gomes e Gomes de Souza (2015)

Sabemos, pois, que a distribuição de Marcuschi (2008) não tem a pretensão de apresentar todos os gêneros textuais existentes, até porque essa seria uma ação muito complexa. $\mathrm{Na}$ distribuição feita no Quadro 1, percebemos maior equilíbrio na distribuição dos domínios discursivos mais frequentes, especialmente nos cinco primeiros. Embora não haja simetria entre os diferentes domínios discursivos, acreditamos que esses percentuais podem servir para um trabalho pautado em maior diversidade textual.

Segundo Marcuschi (2008), o que realmente caracteriza as esferas da atividade humana são as práticas comunicativas que nelas se desenvolvem, pois as rotinas organizam formas de comunicação e estratégias de compreensão típicas. Assim,

os domínios discursivos produzem modelos de ação comunicativa que se estabilizam e se transmitem de geração para geração com propósitos e efeitos definidos e claros. Além disso, acarretam formas de ação, reflexão e avaliação social que 
Linha D'Água (Online), São Paulo, v. 28, n. 2, p. 44-66, dez 2015

determinam formatos textuais que em última instância desembocam na estabilização dos gêneros textuais (MARCUSCHI, 2008, p. 194).

Assim, as variadas esferas da atividade humana comportam as mais diferentes formas comunicativas, estas, por sua vez, expandem-se e transformam-se, num processo ininterrupto. Sobre isso, Bakhtin (1997) argumenta que a diversidade dos gêneros discursivos é imensa, justificando que as possibilidades da atividade humana são inesgotáveis e que, em cada esfera da práxis, existe todo um repertório de gêneros discursivos que se diferencia e cresce à medida que se desenvolve, tornando mais complexa a própria esfera.

\section{Procedimentos metodológicos}

Seguindo as indicações de análise oriundas do ISD, optamos por analisar um documento em uso, ou seja, uma produção linguageira, pois, de acordo com Bronckart (2003), as produções linguagueiras só podem ser encaradas dentro de uma esfera situacional que ofereça as condições contextuais necessárias a sua interpretação. O documento em questão foi a coletânea de livros didáticos Português: linguagens, de Cereja e Magalhães (2010), para o Ensino Fundamental II. Cada volume da coleção foi, assim, codificado: $6^{\circ}$ ano (LDLP1), $7^{\circ}$ ano (LDLP2), $8^{\circ}$ ano (LDLP3) e $9^{\circ}$ ano (LDLP4).

A seleção do objeto levou em consideração que a coleção analisada deveria: a) fazer parte do acervo de coleções de LDLP aprovadas pelo Programa Nacional do Livro Didático (PNLD), por compreendermos que tais coleções passaram pelo crivo de profissionais da área de linguagem; b) explicitar, na sua resenha, contida no Guia de Livros Didáticos de Língua Portuguesa (2007), a ênfase no trabalho com gêneros textuais como objeto de exploração; e c) ser bem avaliada em todos os outros eixos de ensino de língua ao longo do seu processo de didatização. A escolha ocorreu, também, por acreditarmos que, na etapa final do Ensino Fundamental, os alunos mais escolarizados que aqueles dos anos iniciais teriam, relativamente, mais experiências com práticas de leitura e escrita. Além disso, levamos em conta o fato de que, para avaliação dos LDLP desses ciclos, o PNLD preconiza que o material apresente diversidade de gêneros e tipos textuais, distribuídos em atividades de leitura, escrita e oralidade.

Em relação aos desdobramentos da metodologia, utilizamos uma abordagem quali-quantitativa, uma vez que consiste no exame de materiais, visando a uma nova interpretação, posto que as análises qualitativas e quantitativas não se 
Linha D'Água (Online), São Paulo, v. 28, n. 2, p. 44-66, dez 2015

excluem nem se opõem, elas mesclam os procedimentos e contribuem para a melhor compreensão dos fenômenos.

Realizamos, em uma primeira etapa, a análise geral e interpretativa da coleção. A nossa meta foi a de buscar entender se o trabalho com o gênero textual no LDLP é passível de proporcionar ao aluno uma aproximação com a diversidade textual que circula no meio social. Buscamos entendê-la, sobretudo, quanto aos seguintes aspectos: os gêneros textuais, os domínios discursivos dos gêneros textuais e as capacidades de linguagem.

Primeiramente, construímos um quadro geral de todos os gêneros que são objeto de exploração em atividades de leitura, escrita e oralidade, contabilizando as várias recorrências de cada um desses gêneros. Depois, identificamos quais são os domínios discursivos mais e menos enfatizados em cada um dos volumes e na coleção como um todo, procurando entender como os autores da coleção distribuem os gêneros textuais nessa perspectiva. Em seguida, distribuímos os textos detectados nos cinco agrupamentos dispostos por Dolz e Schneuwly (2004): narrar, relatar, argumentar, expor e descrever ações.

Em uma segunda etapa, com base no tratamento didático dos gêneros textuais dado na coleção estudada, apresentamos algumas reflexões e propostas de um trabalho supletivo para as lacunas encontradas.

\section{Análise da distribuição de gêneros textuais no livro didático do Ensino Fundamental}

Dividimos esta seção em dois momentos: o primeiro, a partir da análise da distribuição dos gêneros textuais, visa sugerir uma medida que possibilite o trabalho com a diversidade de gêneros, suprindo as lacunas do LD; e o segundo, com base nos resultados da análise, busca apresentar uma proposta alternativa para o ensino produtivo de língua portuguesa pelos gêneros textuais.

\subsection{Distribuição dos gêneros textuais no livro didático do Ensino Funda- mental}

Iniciamos a análise da coleção didática de língua portuguesa, Português: linguagens (doravante PL), de Cereja e Magalhães (2010), observando a distribuição de gêneros textuais, cujos resultados apresentamos na Tabela 1, que traz, em conjunto, os dados dos volumes dos quatro ciclos (codificados na seção 2): 
Linha D'Água (Online), São Paulo, v. 28, n. 2, p. 44-66, dez 2015

\begin{tabular}{cccccc}
\hline$N^{\circ}$ & $\begin{array}{c}\text { GÊNEROS TEXTUAIS } \\
\text { LDLP1 }\end{array}$ & $\begin{array}{c}\text { GÊNEROS TEXTUAIS } \\
\text { LDLP2 }\end{array}$ & $\begin{array}{c}\text { GÊNEROS TEXTUAIS } \\
\text { LDLP3 }\end{array}$ & $\begin{array}{c}\text { GÊNEROS } \\
\text { TEXTUAIS } \\
\text { LDLP4 }\end{array}$ & $\begin{array}{c}\text { TOTAL } \\
\text { L/R2 }\end{array}$ \\
\hline 01 & Anedota (03) & Anedota (01) & Anedota (02) & Anedota (01) & $04 / 07$ \\
\hline 02 & $\begin{array}{c}\text { Anún. publicitário } \\
(12)\end{array}$ & $\begin{array}{c}\text { Anún. publicitário } \\
(15)\end{array}$ & $\begin{array}{c}\text { Anún. publicitário } \\
(26)\end{array}$ & $\begin{array}{c}\text { Anún. } \\
\text { publicitário (25) }\end{array}$ & $04 / 78$ \\
\hline 03 & & Artigo científico (01) & $01 / 01$ \\
\hline 04 & $\begin{array}{c}\text { Artigo de opinião } \\
(01)\end{array}$ & $\begin{array}{c}\text { Artigo de opinião } \\
(01)\end{array}$ & $02 / 02$ \\
\hline 05 & & \multicolumn{3}{c}{ Aviso (01) } & $01 / 01$ \\
\hline 06 & & Bilhete (02) & $01 / 02$ \\
\hline
\end{tabular}

07 Boxe explicativo (16) Boxe explicativo (12) $\quad$ Boxe explicativo (03) $\begin{array}{ccc}\text { Boxe explicativo } & \text { (09) } & \text { 04/40 }\end{array}$

\begin{tabular}{lccccc}
\hline 08 & Carta pessoal (01) & & 01/.01 \\
\hline 09 & & Carta ao leitor (04) & $01 / 04$ \\
\hline 10 & & $\begin{array}{c}\text { Carta de } \\
\text { reclamação(01) (03) }\end{array}$ & $01 / 01$ \\
\hline 11 & Cartaz (03) & Cartaz (01) & & $02 / 02$ \\
\hline 12 & Cartum (05) & Cartum (02) & Cartum (06) & Cartum (04) & $04 / 17$ \\
\hline 13 & & & Charada (01) & $01 / 01$ \\
\hline 14 & Conto (03) & Conto (03) & Conto (01) & Conto (03) & $04 / 10$ \\
\hline 15 & Conto popular (01) & & & $01 / 01$ \\
\hline 16 & & & C. de casamento & (01) (01) & $01 / 01$ \\
\hline 17 & Crônica (02) & Crônica (01) & Crônica (16) & Crônica (10) & $04 / 29$ \\
\hline 18 & & & & Debate (01) & $01 / 01$ \\
\hline 19 & & Diário pessoal (03) & Diário pessoal (03) & & $01 / 03$ \\
\hline 20 & & & & $02 / 06$ \\
\hline
\end{tabular}

Tabela 1: Gêneros textuais comuns na coleção PL

[Continua] 
Linha D'Água (Online), São Paulo, v. 28, n. 2, p. 44-66, dez 2015

\begin{tabular}{|c|c|c|c|c|c|}
\hline 21 & & & & Editorial (01) & 01/01 \\
\hline 22 & & Entrevista (03) & Entrevista (01) & Entrevista (01) & $03 / 05$ \\
\hline 23 & E-mail (02) & & & & $01 / 02$ \\
\hline 24 & Fábula (04) & Fábula (03) & & & $02 / 07$ \\
\hline 25 & $\begin{array}{l}\text { Hist. em quadrinhos } \\
(01)(04)\end{array}$ & $\begin{array}{l}\text { Hist. em quadrinhos } \\
(01)\end{array}$ & $\begin{array}{l}\text { Hist. em quadrinhos } \\
\text { (01) (01) }\end{array}$ & & $03 / 03$ \\
\hline 26 & Letra de Música (02) & & Letra de Música (01) & $\begin{array}{l}\text { Letra de Música } \\
(01)\end{array}$ & $03 / 04$ \\
\hline 27 & $\begin{array}{c}\text { Manchete de jornal } \\
(01)\end{array}$ & & $\begin{array}{l}\text { Manchete de jornal } \\
(01)\end{array}$ & & $02 / 02$ \\
\hline 28 & & & & Miniconto (04) & $01 / 04$ \\
\hline 29 & & Notícia (02) & Notícia (05) & Notícia (02) & 03/09 \\
\hline 30 & Panfleto (01) & & & & $01 / 01$ \\
\hline 31 & Piada (04) & & Piada (03) & Piada (01) & 03/08 \\
\hline 32 & Poema (13) & Poema (35) & Poema (16) & Poema (24) & $04 / 88$ \\
\hline 33 & Receita culinária (02) & & & & $01 / 02$ \\
\hline 34 & Relato (03) & & & & 0103 \\
\hline 35 & & & & Redação (04) & 01/04 \\
\hline 36 & Reportagem (01) & & Reportagem (03) & $\begin{array}{l}\text { Reportagem } \\
(08)\end{array}$ & $03 / 12$ \\
\hline 36 & & & Resenha crítica (01) & & $01 / 01$ \\
\hline 38 & & & Rótulo (01) & & $01 / 01$ \\
\hline 39 & & Sinopse de filme (01) & & $\begin{array}{l}\text { Sinopse de filme } \\
(01)(01)(02)\end{array}$ & $02 / 01$ \\
\hline 40 & & & Texto teatral (01) & & $01 / 01$ \\
\hline 41 & Tira (45) & Tira (44) & Tira (25) & Tira (31) & $04 / 145$ \\
\hline 42 & $\begin{array}{l}\text { Verb. de dicionário } \\
(01)\end{array}$ & & $\begin{array}{l}\text { Verb. de dicionário } \\
\text { (01) (01) }\end{array}$ & & $02 / 02$ \\
\hline Total & 24 & 16 & 24 & 21 & $85 / 522$ \\
\hline
\end{tabular}

Tabela 1: Gêneros textuais comuns na coleção PL

[Continuação]

Fonte: Figueiredo-Gomes e Gomes de Souza (2015)

2 (L) para livro/ciclo; (R) para recorrência.

FIGUEIREDO-GOMES, J. B.; SOUZA , A. G. UMA REFLEXÃo DIDÁtICA... 
Os dados da Tabela 1 revelam que todas as atividades da coleção visam à exploração de 42 diferentes gêneros, ou seja, um baixo grau de diversidade de gêneros que proporciona aos alunos, ao final de quatro anos letivos, o contato com apenas 42 gêneros distintos.

Uma das principais características da coleção é a abordagem enfática de algumas categorias de gêneros textuais. As quatro categorias mais evidenciadas, tira, poema, anúncio publicitário e boxe explicativo, detêm mais da metade das ocorrências verificadas em toda coleção. A ideia de concentração fica bastante evidente quando observamos que, enquanto o gênero rótulo, por exemplo, foi abordado apenas uma vez nos quatro volumes, o gênero tira teve 145 ocorrências. Os dados apresentados na Tabela 1 mostram que 14 categorias de gêneros textuais estavam presentes em pelo menos três dos quatro volumes. Dessas 14 categorias de gêneros, 8 delas fazem parte do rol de gêneros abordados em todos os volumes da coleção - anedota, artigo publicitário, boxe explicativo, cartum, conto, crônica, poema e tira. Ao todo, constatamos que apenas 21 categorias de gêneros ( $50 \%$ do total) se apresentam, em pelo menos, dois volumes da coleção. A partir desses resultados, pudemos verificar que boa parte dos gêneros textuais disponibilizados pela coleção aparece de maneira isolada, em apenas um dos quatro volumes.

Os dados da Tabela 1 revelam, pois, que há uma significativa descontinuidade no trabalho de alguns gêneros. Exatamente a metade do quantitativo de gêneros (21 categorias) abordada pelo LDLP foi inserida em apenas um dos volumes da coleção, como por exemplo, carta pessoal, conto popular, panfleto, receita culinária e relato, no LDLP1; depoimento escrito, no LDLP2; artigo cientifico, carta ao leitor, charada, resenha crítica, rótulo e texto teatral, no LDLP3; aviso, bilhete, convite de casamento, editorial, miniconto e redação, no LDLP4. A partir desses resultados, foi possível perceber que o LDLP oportuniza ao aluno um único manuseio de cada uma dessas categorias de gênero ao longo do trabalho de quatro anos de escolaridade. No caso do artigo de opinião, por exemplo, que figura no LDLP-1 e no LDLP3, o aluno tem contato com esse gênero no $6^{\circ}$ ano e só vem a ter um próximo contato com o texto dois anos depois, no $8^{\circ}$ ano do ensino fundamental. Esse espaço temporal entre o contato inicial e o próximo contato é muito grande, se considerarmos a hipótese de que o aluno não convive com esse gênero em seu cotidiano extraescolar.

Uma lacuna que constatamos na coleção foi a dos textos advindos das novas tecnologias. Como a coletânea de LDLP selecionada para a pesquisa consta no rol de coleções disponibilizadas aos professores da rede pública de ensino no ano de 2010, chamou-nos à atenção o fato de os textos advindos da internet serem pouco 
frequentes. Em toda coleção, por exemplo, foram apenas cinco aparições em meio a um universo de 522 ocorrências de gêneros.

Outra reflexão que fizemos acerca dos dados gerais da coleção foi a de que, em relação às semelhanças entre os quatro volumes, no tocante à diversidade de gêneros, não conseguimos estabelecer uma gradação coerente, tanto qualitativa quanto quantitativa. Ao contrastarmos os dados, verificamos que os LDLP mais parecidos são o 1 e o 3. Cerca de 72\% dos gêneros textuais apresentados no LDLP1 também estão presentes no LDLP3, as propostas de escrita, leitura e oralidade desses volumes praticamente giram em torno dos mesmos gêneros. Já os volumes que mais divergem em relação à semelhança no trato da diversidade de gêneros são os LDLP 2 e 3 . Pouco mais de 40\% dos gêneros que aparecem no LDLP2 estão presentes no LDLP3.

A segunda etapa buscou verificar quais e como os domínios discursivos (DD), definidos por Marcuschi (2002) como "as grandes esferas da atividade humana em que os textos circulam” (p. 24), são abordados pelo LDLP, a fim de testarmos como a variedade de gêneros textuais existente é explorada segundo os diferentes domínios discursivos. Vejamos, no Quadro 2, a distribuição dos gêneros segundo os domínios discursivos (DD) na coleção:

\begin{tabular}{ll}
\multicolumn{1}{c}{\begin{tabular}{c}
\multicolumn{1}{c}{ DOMÍNIOS } \\
DISCURSIVOS
\end{tabular}} & \multicolumn{1}{c}{ GÊNEROS TEXTUAIS } \\
Jornalístico & $\begin{array}{l}\text { reportagem, manchete de jornal, sinopse de filme, carta de reclamação, carta } \\
\text { ao leitor, resenha crítica, artigo de opinião, entrevista, editorial, notícia, crônica, } \\
\text { relato, história em quadrinhos, tira, cartum }\end{array}$ \\
\hline Ficcional & $\begin{array}{l}\text { fábula, letra de música, texto teatral, miniconto, conto, história em quadrinhos, } \\
\text { poema, conto popular }\end{array}$ \\
\hline Interpessoal & $\begin{array}{l}\text { diário pessoal, carta pessoal, e-mail, relato, convite de casamento, bilhete, } \\
\text { depoimento escrito }\end{array}$ \\
\hline Instrucional & redação, verbete de dicionário, boxe explicativo, artigo científico, debate \\
\hline Lazer & piada, charada, anedota, história em quadrinhos \\
\hline Publicitário & Anúncio publicitário, panfleto, aviso, cartaz \\
\hline Comercial & rótulo \\
\hline Saúde & receita culinária \\
\hline
\end{tabular}

Quadro 2: Distribuição dos gêneros segundo os domínios discursivos na coleção PL

Fonte: Figueiredo-Gomes e Gomes de Souza (2015)

Comentaremos a distribuição dos gêneros segundo os DD na coleção PL do Quadro 2, com base nos percentuais apresentados no Gráfico 2: 
Linha D'Água (Online), São Paulo, v. 28, n. 2, p. 44-66, dez 2015

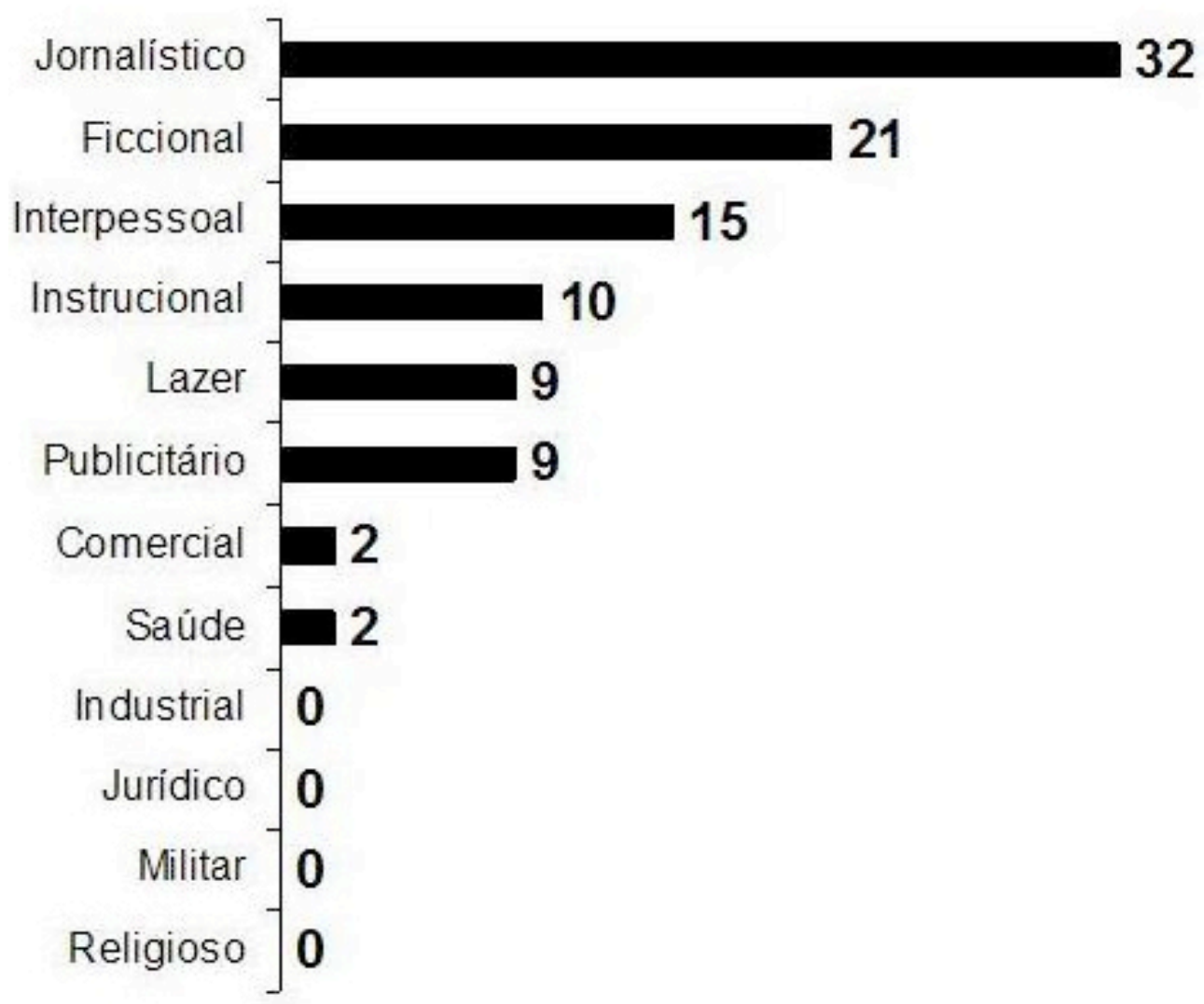

Gráfico 2: Percentuais dos domínios discursivos apresentados pela coleção Português: linguagens Fonte: Figueiredo-Gomes e Gomes de Souza (2015)

Os dados do Gráfico 2 mostram diferentes proporções de alguns DD, havendo uma grande concentração das atividades que têm os gêneros textuais do domínio jornalístico como base. Além desse domínio, os autores também deram ampla ênfase aos textos dos domínios discursivos ficcionais e interpessoais e desprezaram os gêneros de quatro diferentes domínios discursivos, quais sejam: o industrial, o jurídico, o militar e o religioso.

Para fins práticos, comparemos, em termos percentuais, os domínios discursivos apresentados no Gráfico 1, advindos de Marcuschi (2008), e aqueles apresentados pela coleção PL, em estudo, conforme o Gráfico 2. Podemos perceber que os domínios discursivos prioritários em cada proposta são bastante diferentes. Por exemplo, enquanto a coleção PL dá ênfase no trabalho com textos do domínio discursivo jornalístico, a distribuição de Marcuschi (2008) prioriza os gêneros do domínio discursivo instrucional.

Para verificarmos como são agrupados os gêneros textuais da coleção PL no que confere às capacidades de linguagens (CL), atreladas diretamente aos aspectos 
tipológicos, realizamos a terceira etapa da análise dos dados. Para isso, distribuímos os textos encontrados na primeira etapa de análise nas cinco categorias de agrupamentos dispostos por Schneuwly e Dolz (2004). Classificamos, então: a) gêneros da ordem do narrar como a capacidade de linguagem 1 (CL1); b) relatar como CL2; c) argumentar como CL3; d) expor como CL4; e) descrever açóes como CL5. Vejamos, na Tabela 2, quais são as CL mais evidenciadas pelos LDLP por meio dos diferentes gêneros e, mais especificamente, como são representadas em cada um dos ciclos do Ensino Fundamental II.

\begin{tabular}{|c|c|c|c|c|c|}
\hline \multirow{2}{*}{$\begin{array}{l}\text { CAPACIDADE DE } \\
\text { LINGUAGEM }\end{array}$} & \multicolumn{4}{|c|}{ LIVRO DIDÁTICO DE LÍNGUA PORTUGUESA } & \multirow{2}{*}{ TOTAL } \\
\hline & LDLPI & LDLP2 & LDLP3 & LDLP4 & \\
\hline CL1 & 81 & 88 & 55 & 68 & $292 / 56 \%$ \\
\hline CL2 & 15 & 10 & 26 & 22 & $73 / 14 \%$ \\
\hline CL3 & 14 & 16 & 36 & 33 & $99 / 19 \%$ \\
\hline CL4 & 21 & 15 & 7 & 12 & $55 / 10,5 \%$ \\
\hline CL5 & 2 & 0 & 0 & 1 & $3 / 0,5 \%$ \\
\hline Total & $133 / 25,5 \%$ & $129 / 24,5 \%$ & $124 / 24 \%$ & $136 / 26 \%$ & 522 \\
\hline
\end{tabular}

Tabela 2: Gêneros Textuais conforme a capacidade de linguagem na coleção PL

Fonte: Figueiredo-Gomes e Gomes de Souza (2015)

Segundo os dados da Tabela 2, os autores da coleção PL lançam mão da CL1 de maneira bastante acentuada em todos os volumes. No LDLP1 e no LDLP2, os dados referentes a essa categoria são maiores que todas as demais categorias juntas. Isso significa afirmar que os autores inseriram no LDLP muitos gêneros com aspectos tipológicos predominantemente narrativos, muitos oriundos da cultura literária e ficcional. Ainda sobre a CL1, observamos que o trabalho que visa a sua exploração é bem mais intenso nos dois ciclos iniciais e diminui acentuadamente nas demais. Esses resultados comprovam que os autores não dispuseram uma distribuição de gêneros de forma regular nem no que diz respeito aos resultados de cada volume separadamente, nem na gradiência da coleção como um todo.

Verificamos ainda que a incidência da CL3, apesar de intensificada nos dois últimos ciclos, deu-se de maneira mais equilibrada na coleção em geral. As abordagens da CL2, embora tenham ocorrido em todos os volumes, são mais recorrentes nos dois ciclos finais. A distribuição da CL4, ao longo dos ciclos, teve baixa frequência, principalmente no LDLP3. Em termos gerais, essa CL só teve resultado melhor que a CL5. Esta última é dedicada aos textos com aspectos tipológicos 
predominantemente prescritivos e foi a que recebeu menos destaque na coleção, sendo que, no LDLP2 e no LDLP3, por exemplo, não há ocorrência dela. Essa ausência, juntamente com a pouca ocorrência verificada nos LDLP1 e no LDLP4, faz-nos pensar que os autores parecem demandar pouca importância a essa CL.

Toda a análise nos permitiu perceber que, apesar do mérito da proposta, a coleção apresenta problemas no que diz respeito ao número e à diversidade de gêneros enfocados, resultando em um efeito cascata de assimetria entre os gêneros, os domínios discursivos e as capacidades de linguagem. Então, surgiu-nos a indagação: como propor soluções no trabalho com coleções didáticas que apresentam problemas dessa ordem? Esse questionamento nos levou a propor ao professor medidas supletivas a partir dos dados constatados em nossa análise.

Comecemos nossa reflexão sobre o processo de complexificação e/ou adequação dos gêneros, como sugerem Schneuwlye Dolz (2004), quando afirmam que os gêneros devem passar por um processo de progressão, considerando os diferentes níveis de dificuldade no trabalho textual. Segundo os autores, o que determina o grau de complexidade dos textos são os três níveis fundamentais de linguagem em funcionamento: representação do contexto social, estruturação discursiva do texto e escolhas de unidades linguísticas ou textualização. Apoiados em Marcuschi (2002), não acreditamos na existência de gêneros ideais para o ensino de língua materna. Devemos, sim, identificar os gêneros com dificuldades progressivas, trabalhando dos mais simples aos mais complexos, dos mais próximos e conhecidos aos mais distantes, dos mais concretos aos mais abstratos, do nível menos formal ao mais formal, dos mais privados aos mais públicos, e assim por diante.

Não é nosso objetivo apresentar uma proposta de agrupamento de gêneros que contemple essa gradação. Porém, com base nos resultados desta pesquisa, é possível refletir sobre uma proposta supletiva para guiar professores na escolha e análise do LDLP e na adequação à realidade linguística e social do aluno de dado período escolar.

Partamos, pois, da constatação de lacunas no LDLP em relação à distribuição de gêneros. Na análise da coleção, este foi o fator mais problemático. Para contornar situações como essa, o professor poderia fazer a correlação das capacidades de linguagem, de Schneuwly e Dolz (2004), e dos domínios discursivos, sugeridos por Marcuschi (2008), presentes no Quadro 1, e escolher aqueles mais próximos às características dos alunos daquele período escolar.

Uma proposta de distribuição de gêneros que mescle textos de todos os domínios discursivos e capacidades de linguagem pode proporcionar a experimentação da diversidade dos gêneros textuais pelos alunos, tornando o trabalho com a língua materna mais efetivo. Isso porque, de um lado, estão os domínios discursivos, 
intimamente relacionados aos fatores sociais e às diversas categorias de gêneros em seus mais diversos usos autênticos no dia a dia; do outro, estão as capacidades de linguagem, conectadas aos aspectos linguísticos dos gêneros e por isso mais próximas dos modos de interação ou interlocução.

Podemos tomar, então, a relação de gêneros textuais, descrita por Marcuschi (2008) no Quadro 1, como base para apresentarmos uma possibilidade de distribuição de gêneros textuais nos diferentes domínios discursivos tanto para a formatação de LDLP e/ou para suprir as lacunas do LD no ensino de língua materna. Utilizamos os percentuais para refletirmos sobre um possível número de gêneros a ser distribuído num período escolar de um ano, como mostra o Quadro 3:

\begin{tabular}{|cc|}
\hline DOMíNIO DISCURSIVO & No DE GÊNEROS \\
\hline Instrucional & 9 \\
\hline Jornalístico & 6 \\
\hline Interpessoal & 5 \\
\hline Jurídico & 5 \\
\hline Comercial & 4 \\
\hline Ficcional & 3 \\
\hline Publicitário & 2 \\
\hline Religioso & 2 \\
\hline Industrial & 1 \\
\hline Lazer & 1 \\
\hline Saúde & 1 \\
\hline Militar & 1 \\
\hline Total & 40 \\
\hline \hline
\end{tabular}

Quadro 3: Distribuição dos gêneros conforme os domínios discursivos

Fonte: Figueiredo-Gomes e Gomes de Souza (2015)

No Quadro 3, distribuímos um total de 40 gêneros proporcionalmente às porcentagens apresentadas no Gráfico 1. Dessa forma, alguns domínios discursivos foram mais contemplados que outros. Essa diferença nos números reflete a maior incidência dos gêneros de determinado agrupamento e visa aproximar cada categoria de domínio discursivo trabalhada à realidade verificada no meio social, atendendo, assim, ao principal objetivo do ensino de língua, a ampliação da competência comunicativa do aluno.

Quanto às capacidades de linguagem, ligadas aos aspectos tipológicos dos gêneros, utilizamos a "proposta provisória de agrupamento de gêneros" (SCHNEUWLY; DOLZ, 2004, p. 60-61), como referência para a construção da nossa distribuição. Visando a uma distribuição de gêneros equilibrada, pensada para a categorização de Schneuwly e Dolz (2004, p.60-61), optamos por dividir 
os 40 gêneros a serem trabalhados pelas cinco CL, resultando um total de oito gêneros diferentes para cada uma. Dessa forma, todas as categorias de CL seriam trabalhadas uniformemente.

Salientamos que a escolha dos gêneros deve estar atrelada a fatores como a adequação para a etapa do ano letivo, grau de complexidade do gênero, objetivos propostos para o ciclo/escola, modalidades oral e escrita, faixa etária dos alunos, gêneros que favorecem mais a escrita e/ou a leitura. Enfim, seria interessante que essa escolha visasse à seleção dos gêneros mais emblemáticos de cada grupo, tendo em vista a impossibilidade de o LDLP poder abordar todas as categorias de gêneros textuais.

Com base nessa sugestão, o número total de gêneros, incluindo as suas repetições, seria de 160 ocorrências. Esse número é menor que o verificado na coleção PL, que apresentou 522 ocorrências, porém as ocorrências da coleção se pautaram na repetição de categorias. Um trabalho mais consistente com 160 ocorrências de gêneros, voltado à exploração das particularidades dos gêneros, poderia ser bem mais proveitoso.

\subsection{Proposta supletiva para o ensino de Língua Portuguesa por meio de gêneros textuais no LDLP}

Essa proposta visa à resolução de problemas relativos ao ensino a partir dos gêneros textuais. Salientamos que estamos nos baseando em nossa análise e na nossa posição de considerar o LDLP como uma possibilidade didática para o ensino da leitura, da produção textual e da análise linguística.

A proposta, apresentada sinopticamente, divide-se em três etapas: primeiramente, o professor faria uma sondagem e, com base nela, faria a montagem do guia curricular numa segunda etapa. A terceira etapa seria a aplicação do ensino de língua portuguesa por meio do LD e de atividades complementares.

A sondagem seria feita por três instrumentos: a) reconhecimento prévio de gêneros presentes no LDLP por meio de excertos que os caracterizem, mas sem identificação explícita; b) levantamento dos gêneros conhecidos completamente, relativamente ou desconhecido por nome, finalidade e suporte; c) questionário sobre gostos, interesses, práticas sociais e anseios, a fim de compreender a realidade do aluno e apontar-lhe meios para sua participação social efetiva.

A montagem do guia curricular visaria ao planejamento do curso propriamente dito, por meio da: a) correlação entre os dados da sondagem e a coleção de LDLP selecionada; b) seleção dos gêneros que devem ser pouco, medianamente e bastante explorados; c) levantamento das lacunas em relação ao estudo dos gêneros textuais e, com base na distribuição de gêneros apresentadas na seção anterior, propor 
atividades, conforme as capacidades de linguagem e domínios discursivos relativos ao período escolar, que visem à prática efetiva, e não estanque, da leitura, produção de textos e análise linguística.

A aplicação consistira no uso do LDLP, suprindo as lacunas com atividades supletivas que coloquem em diálogo a leitura, a produção textual e a análise linguística com base nos gêneros previstos no guia curricular. Para fins de detalhamento, descrevemos, separadamente, uma amostra de atividades que poderiam auxiliar no ensino dos três eixos basilares de aprendizagem da língua portuguesa, embora saibamos que, na prática, eles interagem entre si. Vejamos, pois, as sugestões em relação às atividades de:

I. Leitura (com base na diversidade de gêneros textuais): a) compreensão do conteúdo temático de gêneros diversos; b) caracterização externa dos gêneros: por meio de questões voltadas para interlocutores, aspectos multimodais, meios de circulação ou suportes textuais, domínio discursivo, função do gênero e contexto comunicativo; c) caracterização interna dos gêneros: por meio de atividades que se voltam para o trabalho com composição, conteúdo, recursos linguísticos, gênero textual, produção textual, tipo textual.

I. Produção de textos (com base no reconhecimento do conjunto de características estudadas na leitura): a) composição e decomposição do gênero em estudo: dividir, recriar, transformar, acrescentar, suprimir ou criar; b) planejamento do texto segundo o gênero: tema, características, objetivo, destinatário e estilo; c) organização das ideias; d) produção do texto propriamente dito; e) editoração do texto; f) revisão do texto e reescritura da versão final.

I. Análise linguística (com base no reconhecimento das características específicas dos gêneros): a) análise das sequências tipológicas; b) reconhecimento das marcas linguísticas específicas ao gênero em foco; c) verificação da variedade e registro linguístico utilizado; d) diferenciação dos padrões linguísticos das modalidades orais e escritas; e) trabalho produtivo com os constituintes gramaticais relativos à fonologia, morfologia, sintaxe, semântica e pragmática; f) exploração do repertório lexical, ampliando-o; g) trabalho com os aspectos convencionais da língua. 
Linha D’Água (Online), São Paulo, v. 28, n. 2, p. 44-66, dez 2015

\section{Conclusão}

Defendemos que a contribuição mais valiosa desta pesquisa tenha sido a de trazer reflexões, operacionalizadas empiricamente, que podem vir a nortear pesquisadores, professores, alunos de graduação e outros profissionais afins, quanto ao uso do LDLP nas aulas de língua materna, no tocante ao trabalho com os gêneros textuais.

As considerações apresentadas nesta pesquisa mostram que a preparação do professor para analisar materiais pedagógicos é de extrema relevância e exige critérios dos mais diversos, mesmo quando se tratar de materiais organizados por especialistas e referendados por políticas públicas de ensino. As particularidades de uma dada situação de aprendizagem só podem ser diagnosticadas pelos próprios docentes, por isso a necessidade de estes estarem cientes de que a escolha de um bom LDLP pode ser decisiva para a aprendizagem, assim como uma experiência frustrada pode desestimular os alunos.

Acreditamos que nossa proposta, apresentada de maneira condensada, favoreça o ensino de língua portuguesa por meio dos gêneros textuais. Ela visa prover os alunos das ferramentas necessárias para agir e interagir no meio social. Seria essa a contribuição do ensino de língua materna para a construção do cidadão atuante. $\mathrm{O}$ ensino que tem como base o trabalho a partir dos gêneros constitui uma maneira concreta de proporcionar a formação de cidadãos no contexto do ambiente escolar.

Dessa forma, concordamos com Bronckart (1999) e Schneuwly e Dolz (2004), quando afirmam que o gênero textual é uma ferramenta que atua no processo de aprendizagem e é encarado como um verdadeiro instrumento para o desenvolvimento das habilidades linguísticas, fornecendo suporte para atividades nas situações de comunicação, tornando produtivo o ensino de língua portuguesa.

Enfim, esperamos que os resultados desta pesquisa, apesar de se voltarem para a análise do LDLP, possam iluminar outras estratégias que visem ao ensino produtivo de língua materna.

\section{Referências}

BAKHTIN, Mikhail. A Estética da Criação Verbal. Os gêneros do discurso. 2a ed. São Paulo: Martins Fontes, 1997.

BRASIL. Secretaria de Educação Fundamental. PCN - Parâmetros Curriculares Nacionais para $3^{\circ}$ e $4^{\circ}$ Ciclos do Ensino Fundamental - Lingua Portuguesa. Brasília, SEF/DF, 1998. 
Linha D’Água (Online), São Paulo, v. 28, n. 2, p. 44-66, dez 2015

. Ministério da Educação. Guia de livros didáticos PNLD 2008: Língua Portuguesa. Brasília: MEC, 2007.

BRONCKART, Jean Paul. Atividade de linguagem, textos e discursos: por um interacionismo sócio-discursivo. Trad. Anna Rachel Machado, Péricles Cunha. São Paulo: EDUC, 1999.

.Gêneros textuais, tipos de discursos e operações psicolinguísticas. Revista deestudos da linguagem,BeloHorizonte,v.11,n.1,p.49-69,jan./jun.2003.DOI:10.17851/2237-2083.11.1.49-69.

CEREJA, Willian Roberto; MAGALHÃES, Thereza Cochar. Português: linguagens. 6. ed. São Paulo: Atual, 2010. (Coleção - Português, Linguagens - 4 volumes - 6º 7 $7^{\circ}, 8^{\circ}$ e $9^{\circ}$ anos).

DOLZ, Joaquim; SCHNEUWLY, Bernard. Gêneros orais e escritos na escola. Trad. e org. Roxane Rojo e Glaís Sales Cordeiro. Campinas: Mercado de Letras, 2004.

MARCUSCHI, Luiz Antônio. Gêneros textuais: definição e funcionalidade. In: DIONÍSIO, Ângela Paiva; MACHADO, Anna Rachel; BEZERRA, Maria Auxiliadora. Gêneros textuais e ensino. São Paulo: Lucerna, 2002, p.19-36.

. Produção textual, análise de gêneros e compreensão. São Paulo: Parábola Editorial, 2008.

SOUZA, Ivane Pedrosa de; LEITE, Tânia Maria Rios; ALBUQUERQUE, Eliana Borges Correia de. Leitura, letramento e alfabetização na escola. In: SOUZA, Ivane Pedrosa de; BARBOSA, Maria Lúcia Ferreira de Figueiredo (org.). Práticas de Leitura no Ensino Fundamental. Belo Horizonte: Autêntica, 2006, p.23-38.

Recebido: 26/06/2015

Aprovado: 16/10/2015 